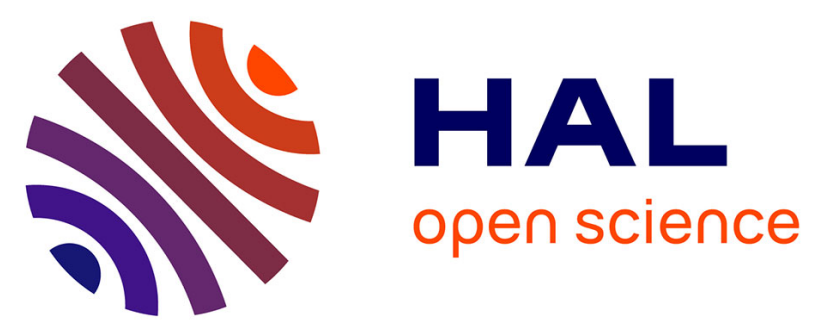

\title{
Diagnostic performance of 18 F-FDG-PET/CT in inflammation of unknown origin (IUO): A clinical series of 317 patients
}

\author{
Jan Holubar, Jonathan Broner, Erik Arnaud, Olivier Hallé, Thibault Mura, \\ Benjamin Chambert, Albert Sotto, Camille Roubille, Cecile Gaujoux-viala, \\ Radjiv Goulabchand
}

\section{To cite this version:}

Jan Holubar, Jonathan Broner, Erik Arnaud, Olivier Hallé, Thibault Mura, et al.. Diagnostic performance of 18 F-FDG-PET/CT in inflammation of unknown origin (IUO): A clinical series of 317 patients. Journal of Internal Medicine, In press, 10.1111/joim.13452 . hal-03524338

\section{HAL Id: hal-03524338 \\ https://hal.science/hal-03524338}

Submitted on 13 Jan 2022

HAL is a multi-disciplinary open access archive for the deposit and dissemination of scientific research documents, whether they are published or not. The documents may come from teaching and research institutions in France or abroad, or from public or private research centers.
L'archive ouverte pluridisciplinaire HAL, est destinée au dépôt et à la diffusion de documents scientifiques de niveau recherche, publiés ou non, émanant des établissements d'enseignement et de recherche français ou étrangers, des laboratoires publics ou privés. 
Diagnostic performance of ${ }^{18} \mathrm{~F}$-FDG-PET/CT in inflammation of unknown origin (IUO): a clinical series of 317 patients

\section{Running head:}

Diagnostic performance of ${ }^{18} \mathrm{~F}$-FDG-PET/CT in IUO

Dr Jan Holubar ${ }^{1, *}$, Dr Jonathan Broner ${ }^{1,}{ }^{,}$, Dr Erik Arnaud ${ }^{1}$, Dr Olivier Hallé ${ }^{2}$, Pr Thibault Mura ${ }^{3}$, Dr Benjamin Chambert ${ }^{4}$, Pr Albert Sotto ${ }^{5}$, Dr Camille Roubille ${ }^{6}$, Pr Cecile Gaujoux-Viala ${ }^{7,8}$, Dr Radjiv Goulabchand $^{1,9}$

${ }^{1}$ Internal Medicine department, CHU Nîmes, Univ Montpellier, Nîmes, France

${ }^{2}$ Internal medicine department 2, CH Ales-Cevennes, Ales, France

${ }^{3}$ Department of Biostatistics, Clinical Epidemiology, Public Health, and Innovation in Methodology, CHU Nîmes, Univ Montpellier, Nîmes, France

${ }^{4}$ Department of Nuclear Medicine, CHU Nimes, Univ Montpellier, Nimes, France

${ }^{5}$ Department of Infectious and Tropical Diseases, CHU Nîmes, Univ Montpellier, France

${ }^{6}$ Department of Internal medicine, Lapeyronie Hospital, Montpellier University Hospital, Montpellier, France; Univ Montpellier; PhyMedExp, University of Montpellier, INSERM U1046, CNRS UMR 9214, Montpellier, France.

${ }^{7}$ Department of Rheumatology, CHU Nîmes, Nîmes, France

8 UA11 Institut Desbrest d'Épidémiologie et de Santé Publique, Univ Montpellier, INSERM, Montpellier, France

${ }^{9}$ IRMB, University of Montpellier, INSERM, Montpellier, France

*Both authors contributed equally to this work

\section{ABSTRACT}

Background: Inflammation of unknown origin (IUO) is a challenging situation in internal medicine.

Objectives: To describe the final diagnoses in IUO and assess ${ }^{18} \mathrm{~F}$-FluoroDesoxyGlucose PositronEmission-Tomography with Computerized Tomography $\left({ }^{18} \mathrm{~F}-\mathrm{FDG}-\mathrm{PET} / \mathrm{CT}\right)$ helpfulness in the diagnosis strategy. 
Results: 317 IUO patients with ${ }^{18}$ F-FDG-PET/CT were enrolled. A diagnosis was reached in 228 patients: non-infectious inflammatory diseases (NIID) (37.5\%), infectious diseases (18.6\%), malignancies (7.9\%) and non-systemic-inflammatory miscellaneous diseases (7.9\%). The two leading causes of NIID were polymyalgia rheumatica and giant cell arteritis. ${ }^{18} \mathrm{~F}-\mathrm{FDG}$-PET/CT results were classified as True Positive in $49.8 \%$ patients, and contributory in $75.1 \%$ of overall IUO patients (after the complete investigation set and a prolonged follow-up). In multivariate analysis, only CRP minimum level $(\geq 50 \mathrm{mg} / \mathrm{l})$ was associated with the contributory status of ${ }^{18} \mathrm{~F}$-FDG-PET/CT.

Conclusion: Within the wide spectrum of IUO underlying diseases, ${ }^{18} \mathrm{~F}-\mathrm{FDG}-\mathrm{PET} / \mathrm{CT}$ is helpful to make a diagnosis, and to eliminate inflammatory diseases. Obese patients constitute a specific group needing further studies.

\section{Keywords:}

Inflammation of unknown origin, Fever of unknown origin, PET-CT, ${ }^{18}$ F-FDG-PET/CT, Giant cell arteritis, Polymyalgia Rheumatica, obesity

\section{INTRODUCTION}

Internists manage a wide variety of clinical issues, including fever of unknown origin (FUO) and inflammation of unknown origin (IUO). ${ }^{18}$ F-FluoroDesoxyGlucose Positron Emission Tomography with Computerized Tomography $\left({ }^{18} \mathrm{~F}-\mathrm{FDG}-\mathrm{PET} / \mathrm{CT}\right)$ appears to be a high-performance $[1,2]$ and costeffective tool for diagnosing FUO [3]. IUO is defined as a prolonged and unexplained inflammatory syndrome, for which final diagnoses are heterogeneous [4-6]. Currently, ${ }^{18}$ F-FDG-PET/CT is widely used in the diagnosis strategy for investigating IUO, but it is not yet clearly validated $[3,5,6]$.

The aim of this study was to describe the final diagnoses made in patients with IUO after a diagnosis strategy involving ${ }^{18} \mathrm{~F}-\mathrm{FDG}-\mathrm{PET} / \mathrm{CT}$, and to assess the diagnostic performance of this investigation (sensitivity, specificity, predictive values).

\section{METHODS}

\section{Study design and data collection}

This retrospective observational study included adult patients with IUO and a ${ }^{18}$ F-FDG-PET/CT performed in our tertiary university hospital for an "inflammatory" reason. IUO was defined by a Creactive protein (CRP) blood level $\geq 5 \mathrm{mg} / \mathrm{l}$, measured at least twice, lasting $\geq 3$ weeks, and remaining unexplained. ${ }^{18}$ F-FDG-PET/CTs performed for exploring a mass or tumour or in case of a previously 
suspected diagnosis were excluded. Fever was not an exclusion criterion, except when fulfilling FUO criteria: lasting $\geq 3$ weeks or recurrent.

\section{Outcomes}

The final diagnosis was the one retained by the referring clinician. Final diagnoses were classified into four categories: (i) non-infectious inflammatory diseases (NIID), including vasculitides and inflammatory joint diseases; (ii) infectious diseases; (iii) neoplasms; and (iv) non-systemicinflammatory miscellaneous (NSIM) diseases. In disputed cases, medical files were reviewed by two independent experts, blinded to the suspected diagnosis, and we contacted the general practitioner or the patient to ascertain the diagnosis. In some cases, no diagnosis was made. The validity of "no diagnosis" was enhanced by a prolonged follow-up.

According to the final diagnosis, the result of the ${ }^{18} \mathrm{~F}$-FDG-PET/CT was classified as true positive (TP), true negative (TN), false positive (FP) or false negative (FN) (definitions in Supplementary e-method and Figure 2A). ${ }^{18}$ F-FDG-PET/CT results classified as TP or TN were defined as contributory. A detailed ${ }^{18} \mathrm{~F}$-FDG-PET/CT technical procedure is available as Supplementary e-method.

\section{Statistical analyses}

Description of general characteristics of the population, and subgroups analyses involved classical statistical tests. To describe ${ }^{18} \mathrm{~F}-\mathrm{FDG}-\mathrm{PET} / \mathrm{CT}$ performance, we calculated the positive predictive value (PPV), the negative predictive value (NPV), the sensitivity and the specificity.

After testing the association between baseline characteristics and the final diagnoses or the contributory status of ${ }^{18} \mathrm{~F}$-FDG-PET/CT, we selected relevant characteristics for multivariate analyses (multivariate logistic binary regression). All analyses were performed using SAS software (SAS ${ }^{\circledR}$ 9.4; SAS institute inc., Cary, NC, USA).

\section{Ethical issues}

Our study was conducted in accordance with the ethical committee of the University Hospital of Nimes (institutional review board number 19.09.03).

\section{RESULTS}

\section{Baseline characteristics}

The selection of the study population is presented in Supplementary Figure 1. Among the 317 patients included, $48.9 \%$ were female, with a mean age of 66.4 years, and a mean duration of IUO of 5.2 months. The characteristics of the population are listed in Table 1. No investigation was 
performed after the ${ }^{18}$ F-FDG-PET/CT in 135 (43\%) patients. We recorded 30 deaths (10.5\%). The mean follow-up was $19 \pm 23$ months (457 person-years).

\section{Diagnoses}

A diagnosis was made in 228 patients (71.9\%) (Figure 1): NIID (37.5\%), infectious diseases (18.6\%), malignancies (7.9\%) and non-systemic-inflammatory miscellaneous (NSIM) diseases (7.9\%). Polymyalgia rheumatica (PMR) and giant cell arteritis (GCA) concerned, respectively, $13.6 \%$ and $14.0 \%$ of all diagnoses. No diagnosis was reached in 89 (28.1\%) patients. Baseline characteristics according to the presence of a final diagnosis and according to the diagnostic groups are shown in Supplementary Tables 1 and 2.

In multivariate binary analysis integrating age, sex, fever, obesity, and CRP minimum level, we found that age $\geq 50$ years, presence of fever, absence of obesity, and a CRP minimum level $\geq 50 \mathrm{mg} / \mathrm{l}$ increased the likelihood of a final diagnosis (respectively, $\mathrm{HR}=2.03,95 \% \mathrm{Cl}$ [1.06-3.87]; $\mathrm{HR}=2.01,95 \%$ $\mathrm{Cl}$ [1.01-4.04], $\mathrm{HR}=2.19,95 \% \mathrm{Cl}$ [1.05-4.54], and $\mathrm{HR}=2.14,95 \% \mathrm{Cl}$ [1.18-3.90]) (Figure 2B).

Thirty-nine IUO patients were obese (female in $72 \%$, mean age of 57.1 years). In comparison with the other patients, they were younger, showed less fever and had a lower mean CRP level, but a longer duration of increased CRP. Of these 39 patients, $51.3 \%$ received no diagnosis. The diagnosis rate was poor (39\%) for obese patients with a CRP minimum level $<50 \mathrm{mg} / \mathrm{l}$ (no cancer).

\section{${ }^{18}$ F-FDG-PET/CT contribution}

${ }^{18}$ F-FDG-PET/CT results were classified as TP in 158 patients (49.8\%), TN in 80 (25.2\%), FP in 48 (15.1\%) and FN in 31 (9.9\%) (Figure 2A). Thus, ${ }^{18} \mathrm{~F}$-FDG-PET/CT had a sensitivity of $83.6 \%$, a specificity of $62.5 \%$, a PPV of $76.7 \%$, and a NPV of $72.1 \%$. ${ }^{18}$ F-FDG-PET/CT was classified as contributory in $75.1 \%$ of global IUO patients, and $78.9 \%$ of patients with a final diagnosis.

${ }^{18}$ F-FDG-PET/CT was contributory for each diagnosis subcategory, including the group without diagnosis (Supplementary Table 2 and 3). In a multivariate binary analysis integrating age, sex, obesity, fever, and CRP minimum level, the CRP minimum level $\geq 50 \mathrm{mg} / \mathrm{L}$ was an independent factor associated with the contribution of ${ }^{18} \mathrm{~F}-\mathrm{FDG}-\mathrm{PET} / \mathrm{CT}(\mathrm{HR}=2.11,95 \% \mathrm{Cl}$ [1.17-3.83], $\mathrm{p}=0.014)$.

\section{DISCUSSION}

\section{Case-mix in IUO patients}

The repartition of diagnoses is similar to literature data [4-6]. We confirm previous data identifying GCA and PMR as the two leading causes of NIID among IUO patients [4-7]. A high proportion of 
patients with NIID did not have further investigation after the ${ }^{18} \mathrm{~F}-\mathrm{FDG}-\mathrm{PET} / \mathrm{CT}$, highlighting the potential impact of ${ }^{18} \mathrm{~F}$-FDG-PET/CT on health consumption in these diseases.

Among rarer causes of NIID, we found one case of relapsing polychondritis and one case of IgG4 related disease (IgG4RD), in accordance with a previous study [8]. Compared to us, Schönau et al. found a higher prevalence of IgG4RD. This might be explained by the different patient populations (younger patients in a referring department for immune-inflammatory diseases) [6]. Moreover, IgG4RD rarely presents as an isolated inflammatory syndrome [9].

We found that osteoarthritis was frequent among NSIM diseases associated with IUO. This is unsurprising considering that inflammatory pathways are active in osteoarthritis [10], the older age of affected patients, and the interaction of osteoarthritis with obesity.

\section{Factors associated with reaching a final diagnosis in IUO}

Our study demonstrates that CRP level $\geq 50 \mathrm{mg} / \mathrm{l}$, age $\geq 50$ years old, absence of obesity and presence of fever are correlated with obtaining a diagnosis among patients with IUO.

Interestingly, the diagnosis rate in obese patients was poor, especially when minimum CRP level was $<50 \mathrm{mg} / \mathrm{l}$. These obese patients with IUO were younger female patients, with lower CRP mean levels, and longer CRP duration, for whom ${ }^{18}$ F-FDG-PET/CT could be a good tool to eliminate inflammatory diseases, and thus avoid invasive (and potentially dangerous) procedures. The link between obesity and microinflammation is well known [11]. CRP level is often slightly elevated in obese patients, and specific investigations are controversial $[5,12]$. However, we report here high levels of CRP ( $\geq 20 \mathrm{mg} / \mathrm{l})$ related to obesity, which has not been frequently described $[5,13]$.

\section{Factors associated with ${ }^{18}$ F-FDG-PET/CT contribution in IUO}

The ${ }^{18}$ F-FDG-PET/CT was contributory in $75 \%$ of IUO patients, highlighting its helpfulness in investigating IUO [5,6]. This diagnostic contribution for the two leading causes of NIID in IUO, GCA and PMR, supports the published literature [14-17].

We found that CRP level was a predictive factor to the contributory status of ${ }^{18}$ F-FDG-PET/CT in investigating IUO $[5,18]$. However, in contrast to Schönau et al., age and fever were not significantly correlated with the ${ }^{18}$ F-FDG-PET/CT benefit, although their study also included FUO patients. We decided to focus on pragmatic and easily identifiable markers; CRP minimum level was thus preferred, rather than previously reported CRP level at acute phase [6] or CRP level closest to ${ }^{18} \mathrm{~F}$ FDG-PET/CT $[5,18]$. 


\section{Strengths and limits}

To our knowledge, this is the largest study involving IUO. We performed a "real-life" study based on all the ${ }^{18} \mathrm{~F}$-FDG-PET/CT performed in our area. The indication for ${ }^{18} \mathrm{~F}$-FDG-PET/CT was decided by physicians for a wide spectrum of clinical situations, while other studies focused on joint or infectious diseases $[3,16]$. As all patients were referred to a single nuclear medicine department, technical bias or misinterpretation were limited $[6,8]$. Our results are therefore highly transposable to the general "real-life" population of IUO patients.

To better reflect the real ${ }^{18} \mathrm{~F}$-FDG-PET/CT performance, we decided to classify ${ }^{18} \mathrm{~F}-\mathrm{FDG}-\mathrm{PET} / \mathrm{CT}$ results as TN not only when ${ }^{18}$ F-FDG-PET/CT was normal and no diagnosis was performed [6], but also when a non-inflammatory diagnosis was made (with no expected ${ }^{18}$ F-FDG-PET/CT abnormal uptake). Moreover, we considered that a TN ${ }^{18} \mathrm{~F}-\mathrm{FDG}-\mathrm{PET} / \mathrm{CT}$ was as contributory as a TP result [5]. We assumed that ${ }^{18} \mathrm{~F}$-FDG-PET/CT TN results were helpful in making a diagnosis, or in eliminating a potentially severe inflammatory disease, and thus limiting further investigations. However, ${ }^{18}$ F-FDGPET/CTs classified as TP are not associated with less complementary investigations, since other tests may be needed to confirm the suspected diagnosis.

Nevertheless, our study has some limitations. First, we did not include IUO patients without ${ }^{18}$ F-FDG$\mathrm{PET} / \mathrm{CT}$. Only one study has compared the efficiency of ${ }^{18} \mathrm{~F}-\mathrm{FDG}-\mathrm{PET} / \mathrm{CT}$ in IUO, finding it to be costeffective and contributory for the diagnosis [19]. Larger studies did not have a comparative group without ${ }^{18}$ F-FDG-PET/CT [6]. Moreover, in France, ${ }^{18}$ F-FDG-PET/CT is widely available and used, despite not having been validated in IUO diagnosis strategy [3].

Secondly, we set a minimal CRP level threshold $>5 \mathrm{mg} / \mathrm{l}$ as an inclusion criterion, that could be considered normal. However, the mean CRP minimum level was above $40 \mathrm{mg} / \mathrm{l}$, reflecting a population of "true" IUO. We included patients with fever, except in the cases where fever fulfilled the FUO criteria. Short-term fever may be present in NIID, and we thus could not exclude those patients.

Another limitation is the determination of a subgroup of IUO patients with "no diagnosis", as classification is only possible after a prolonged follow-up with a complete set of investigations. Nevertheless, compared to literature data, our mean follow-up of $>19$ months was sufficient as compared to 12 months [4], >2 years [5], and $\geq 3$ months [6], and the proportion of "no diagnosis" was similar to previous studies (39\% [4] and 26\% [5]). We also suggest that this follow-up is long enough to make the diagnosis of infection, cancer, or autoimmune disease. In $30 \%$ of these IUO patients with "no diagnosis", the inflammatory syndrome resolved spontaneously. 
The high diagnostic performance of ${ }^{18}$ F-FDG-PET/CT has to be tempered by the 31 cases of FN ( 2 cancers, 3 GCA and 12 infections). These likely arose from the high frequency of glucocorticoid treatment within this subgroup, thus negative ${ }^{18}$ F-FDG-PET/CT results in patients under glucocorticoid therapy should be interpreted with caution. Nonetheless, we decided to include these patients in the analyses because they had persistent inflammation despite this treatment, and because our study was conceived to reflect everyday practice [6]. FP were also reported in 48 cases, followed by colonoscopies. Indeed, the classification of digestive uptake as specific or non-specific remains challenging, and can sometimes only be confirmed after colonoscopy results. Specific guidelines to clarify the interpretation of digestive uptake will decrease unnecessary invasive exams [20]. In our study, the prolonged follow-up confirmed the accuracy of those FP cases.

These FP and FN highlight that ${ }^{18}$ F-FDG-PET/CT alone cannot replace a cautious diagnosis strategy involving repeated examinations, and prolonged follow-up. We cannot provide here a guided diagnosis strategy for IUO. A personalised combination of clinical, biological, and appropriate imaging (sometimes including ${ }^{18} \mathrm{~F}$-FDG-PET/CT) will always help to tailor the diagnosis strategy, avoiding unnecessary, invasive, and costly tests.

\section{CONCLUSION}

This large study involving "real-life" patients with IUO demonstrates that ${ }^{18} \mathrm{~F}-\mathrm{FDG}-\mathrm{PET} / \mathrm{CT}$ is a helpful tool in the diagnosis strategy, ascertaining the diagnosis or eliminating systemic inflammatory disease in $75 \%$ of patients. In patients with a CRP minimum level $\geq 50 \mathrm{mg} / \mathrm{l}$, the contribution of the

${ }^{18} \mathrm{~F}$-FDG-PET/CT increases to $83 \%$. The impact of ${ }^{18} \mathrm{~F}-\mathrm{FDG}-\mathrm{PET} / \mathrm{CT}$ in limiting investigations among young obese patients with a low CRP level should be addressed in prospective studies.

\section{CONFLICT OF INTEREST STATEMENT}

All authors declare to have no conflict of interest concerning this article

\section{ACKNOWLEDGEMENTS}

We sincerely thank Sarah Kabani for editing assistance. 


\section{AUTHOR CONTRIBUTION}

Conceptualization (JH, JB, EA, RG); Data curation (JH, JB, RG, TM, BC); Formal analysis (JH, JB, RG, TM); Funding acquisition (N/A); Investigation (JH, JB, BC, OH); Methodology (JB, EA, RG, TM, CGV); Project Administration (JB, RG); Resources (JB, EA, TM); Software (RG, TM); Supervision (EA, CGV, $T M, A S, C R)$; Validation (JH, JB, RG, EA); Visualization (JH, JB, RG); Writing original draft \& editing (JH, $\mathrm{JB}, \mathrm{TM}, \mathrm{CGV}, \mathrm{RG})$; Writing review \& editing (JH, JB, EA, OH, TM, BC, AS, CR, CGV, RG).

\section{REFERENCES}

1. Besson FL, Chaumet-Riffaud P, Playe $M$, et al. Contribution of (18)F-FDG PET in the diagnostic assessment of fever of unknown origin (FUO): a stratification-based meta-analysis. Eur J Nucl Med Mol Imaging 2016; 43: 1887-95.

2. Letertre S, Fesler P, Zerkowski L, et al. Place of the 18F-FDG-PET/CT in the Diagnostic Workup in Patients with Classical Fever of Unknown Origin (FUO). J Clin Med 2021; 10: 3831.

3. Casali M, Lauri C, Altini C, et al. State of the art of 18F-FDG PET/CT application in inflammation and infection: a guide for image acquisition and interpretation. Clin Transl Imaging 2021: 1-41.

4. Vanderschueren S, Del Biondo E, Ruttens D, Van Boxelaer I, Wauters E, Knockaert DDC. Inflammation of unknown origin versus fever of unknown origin: two of a kind. Eur $J$ Intern Med 2009; 20: 415-8.

5. Balink H, Bennink RJ, Veeger NJGM, van Eck-Smit BLF, Verberne HJ. Diagnostic utility of (18)F-FDG PET/CT in inflammation of unknown origin. Clin Nucl Med 2014; 39: 419-25.

6. Schönau V, Vogel K, Englbrecht M, et al. The value of ${ }^{18}$ F-FDG-PET/CT in identifying the cause of fever of unknown origin (FUO) and inflammation of unknown origin (IUO): data from a prospective study. Ann Rheum Dis 2018; 77: 70-7.

7. Prieto-Peña D, Castañeda S, Atienza-Mateo B, Blanco R, González-Gay MA. Predicting the risk of relapse in polymyalgia rheumatica: novel insights. Expert Rev Clin Immunol 2021; 17: 225-32.

8. Wang $\mathrm{Q}$, Li Y-M, Li Y, et al. 18F-FDGPET/CT in fever of unknown origin and inflammation of unknown origin: a Chinese multi-center study. Eur J Nucl Med Mol Imaging 2019; 46: 159-65.

9. Satou A, Notohara K, Zen Y, et al. Clinicopathological differential diagnosis of IgG4-related disease: A historical overview and a proposal of the criteria for excluding mimickers of IgG4-related disease. Pathol Int 2020; 70: 391-402.

10. Berenbaum F, Walker C. Osteoarthritis and inflammation: a serious disease with overlapping phenotypic patterns. Postgrad Med 2020; 132: 377-84.

11. Pahk K, Kim EJ, Lee Y-J, Kim S, Seo HS. Characterization of glucose uptake metabolism in visceral fat by 18 F-FDG PET/CT reflects inflammatory status in metabolic syndrome. PloS One 2020; 15: 
e0228602.

12. Ishii S, Karlamangla AS, Bote $M$, et al. Gender, obesity and repeated elevation of C-reactive protein: data from the CARDIA cohort. PloS One 2012; 7: e36062.

13. Schönau V, Schett G. Response to: the value of 18(F)-FDG-PET/CT in identifying the cause of fever of unknown origin (FUO) and inflammation of unknown origin (IUO): data from a prospective study. Ann Rheum Dis 2017.

14. Emamifar A, Ellingsen T, Hess S, et al. The Utility of 18F-FDG PET/CT in Patients With Clinical Suspicion of Polymyalgia Rheumatica and Giant Cell Arteritis: A Prospective, Observational, and Cross-sectional Study. ACR Open Rheumatol 2020; 2: 478-90.

15. Prieto-Peña D, Castañeda S, Martínez-Rodríguez I, Atienza-Mateo B, Blanco R, González-Gay MA. Imaging Tests in the Early Diagnosis of Giant Cell Arteritis. J Clin Med 2021; 10: 3704.

16. van der Geest KSM, Treglia G, Glaudemans AWJM, et al. Diagnostic value of [18F]FDG-PET/CT in polymyalgia rheumatica: a systematic review and meta-analysis. Eur J Nucl Med Mol Imaging 2021; 48: 1876-89.

17. González-Gay MA, Prieto-Peña D, Martínez-Rodríguez I, et al. Early large vessel systemic vasculitis in adults. Best Pract Res Clin Rheumatol 2019; 33: 101424.

18. Balink $\mathrm{H}$, Veeger NJGM, Bennink RJ, et al. The predictive value of C-reactive protein and erythrocyte sedimentation rate for 18F-FDG PET/CT outcome in patients with fever and inflammation of unknown origin. Nucl Med Commun 2015; 36: 604-9.

19. Balink H, Tan SS, Veeger NJGM, et al. ${ }^{18}$ F-FDG PET/CT in inflammation of unknown origin: a costeffectiveness pilot-study. Eur J Nucl Med Mol Imaging 2015; 42: 1408-13.

20. Liu T, Behr S, Khan S, Osterhoff R, Aparici CM. Focal Colonic FDG Activity with PET/CT: Guidelines for Recommendation of Colonoscopy. World J Nucl Med 2015; 14: 25-30.

\section{Corresponding author:}

Dr Radjiv Goulabchand: radjiv.goulabchand@chu-nimes.fr 


\section{FIGURE LEGENDS}

Figure 1: Repartition of the final 228 diagnoses assessed in 317 patients with inflammation of unknown origin, after a complete set of investigations including ${ }^{18}$ F-FDG-PET/CT.

NIID: non-infectious inflammatory diseases; NSIM, Non systemic-inflammatory miscellaneous diseases

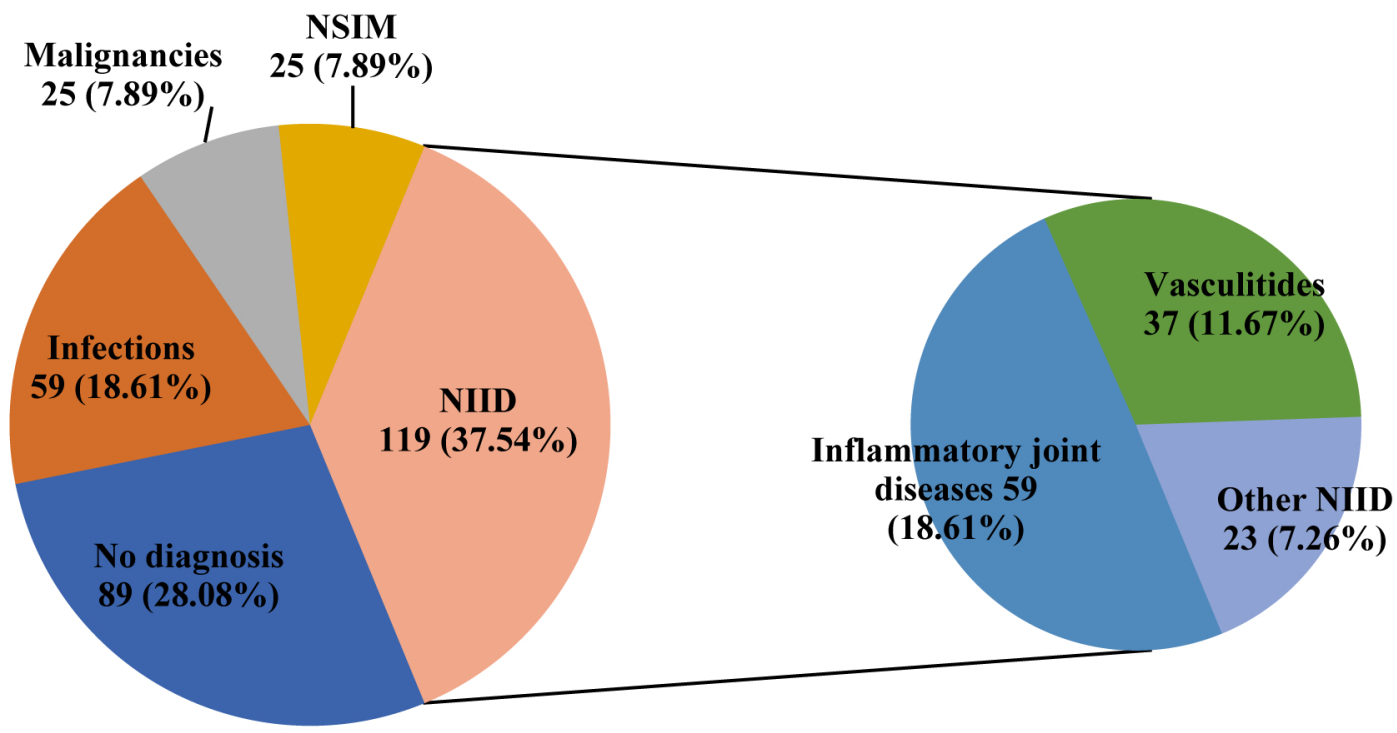

Non-systemic-inflammatory miscellaneous

diseases $(n=25)$

\begin{tabular}{lcc}
\hline Osteoarthritis & 7 & $28.0 \%$ \\
Pericarditis & 3 & $12.0 \%$ \\
Aseptic osteonecrosis & 2 & $8.0 \%$ \\
Arterial dissection & 2 & $8.0 \%$ \\
Serous effusions & 2 & $8.0 \%$ \\
Benign tumours & 2 & $8.0 \%$ \\
Cardiac failure & 1 & $4.0 \%$ \\
Glomerulonephritis & 1 & $4.0 \%$ \\
Deep vein thrombosis & 1 & $4.0 \%$ \\
Acute hepatitis & 1 & $4.0 \%$
\end{tabular}


Skin ulcers

Amyloid angiopathy

Medication side effect
$1 \quad 4.0 \%$

$1 \quad 4.0 \%$

$1 \quad 4.0 \%$
Non-infectious inflammatory diseases $(n=119)$

\begin{tabular}{|c|c|c|}
\hline \multicolumn{3}{|l|}{ Inflammatory joint diseases $(n=59)$} \\
\hline Polymyalgia rheumatica & 31 & $52.5 \%$ \\
\hline Rheumatoid arthritis & 15 & $25.4 \%$ \\
\hline seronegative & 9 & $15.3 \%$ \\
\hline seropositive & 6 & $10.2 \%$ \\
\hline Spondyloarthropathies & 10 & $17.0 \%$ \\
\hline Psoriatic arthritis & 3 & $5.1 \%$ \\
\hline Pseudogout & 3 & $5.1 \%$ \\
\hline \multicolumn{3}{|l|}{ Vasculitides $(n=37)$} \\
\hline Giant cell arteritis & 32 & $86.5 \%$ \\
\hline Microscopic polyangiitis & 2 & $5.4 \%$ \\
\hline Granulomatous polyangiitis & 1 & $2.7 \%$ \\
\hline Relapsing polychondritis & 1 & $2.7 \%$ \\
\hline Other & 1 & $2.7 \%$ \\
\hline
\end{tabular}

Other NIID $(n=23)$

\begin{tabular}{|c|c|c|}
\hline Adult onset Still's disease & 5 & $21.7 \%$ \\
\hline Inflammatory bowel diseases & 4 & $17.4 \%$ \\
\hline Sarcoidosis & 4 & $17.4 \%$ \\
\hline Systemic lupus erythematosus & 2 & $8.7 \%$ \\
\hline Unclassified connective tissue disease & 2 & $8.7 \%$ \\
\hline IgG4-related disease & 1 & $4.3 \%$ \\
\hline Other & 5 & $21.7 \%$ \\
\hline
\end{tabular}




\section{Figure 2:}

(A) ${ }^{18}$ F-FDG-PET/CT diagnostic performance according to the final diagnosis of each patient.

Sensitivity $83.6 \%$; Specificity $62.5 \%$. Within our study population, the positive predictive value of ${ }^{18} \mathrm{~F}$ FDG-PET was $76.7 \%$ and the negative predictive value was $72.1 \%$.

${ }^{18}$ F-FDG-PET/CT, 18F-fluorodesoxyglucose positron emission tomography with computerized tomography. True positive (TP): abnormal ${ }^{18} F-F D G$ uptake that lead to or was consistent with the final diagnosis of an inflammatory disease. True negative (TN): no abnormal uptake in the cases where no inflammatory disease was diagnosed or in the cases where no diagnosis was made. False positive (FP): abnormal uptake not consistent with the final cause of IUO. False negative (FN): absence of abnormal uptake, while the final diagnosis was supposed to be targeted by ${ }^{18}$ F-FDG.

(B) Proportion of final diagnoses assessed after a complete investigation set including a ${ }^{18}$ F-FDG$\mathrm{PET} / \mathrm{CT}$, in 317 patients with inflammation of unknown origin, according to baseline characteristics.

IUO, inflammation of unknown origin; CRP min: minimum level of C-reactive protein level; $n$, describes the numbers of patients in each subcategory. Darker colours are associated with higher percentage of final diagnosis.

(A)

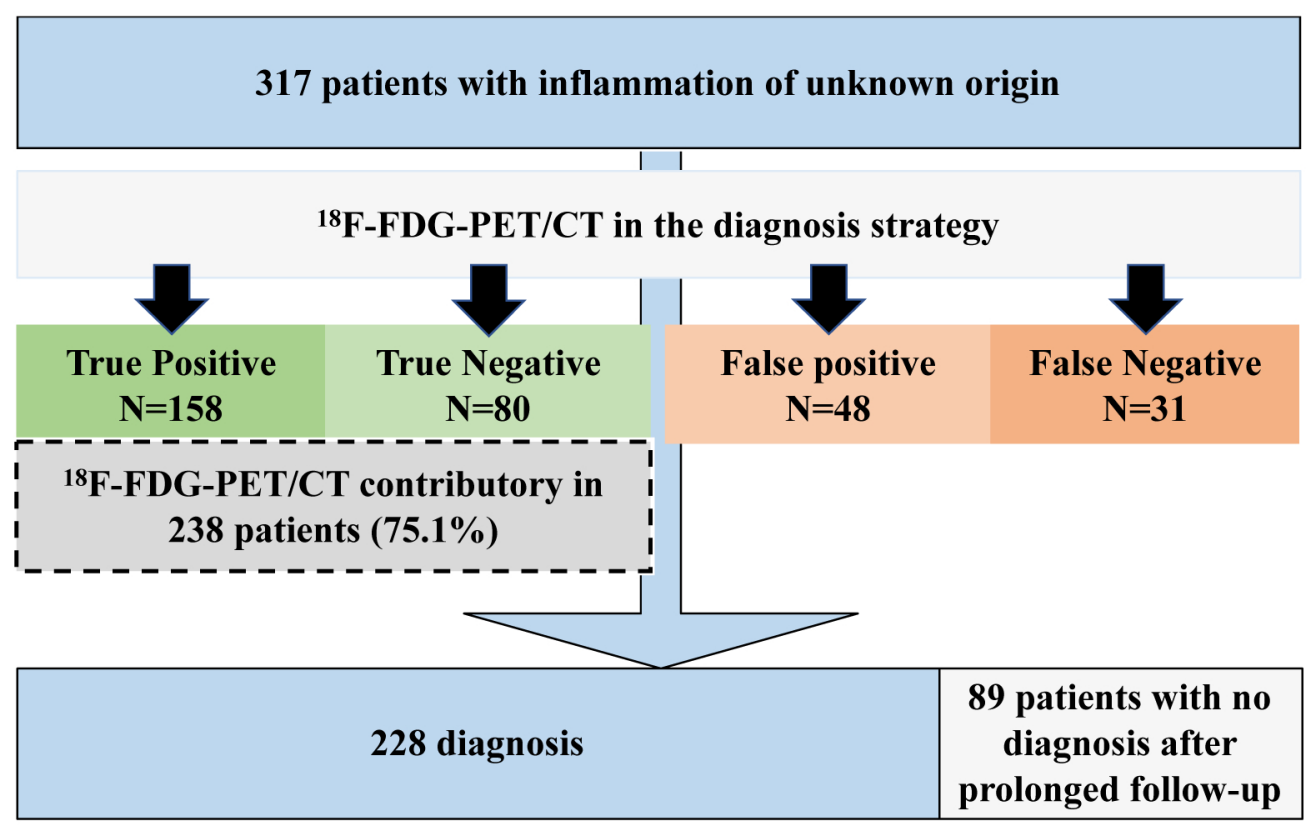

(B)

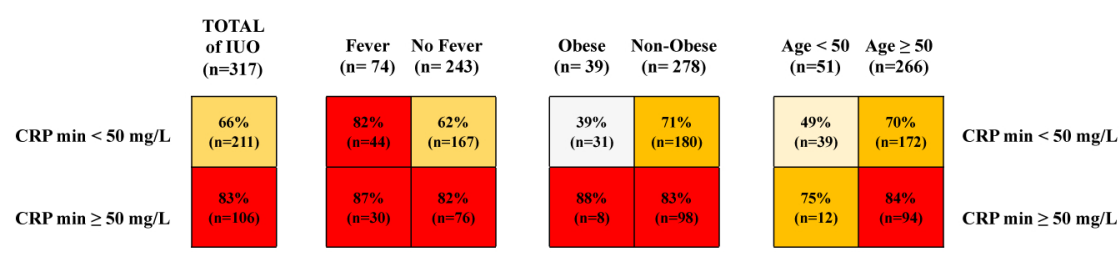




\section{TABLES}

Table 1: Demographical, clinical, biological characteristics and details of investigations for the 317 patients with inflammation of unknown origin, with a diagnosis strategy involving ${ }^{18} \mathrm{~F}-\mathrm{FDG}-\mathrm{PET} / \mathrm{CT}$

Characteristics of the study population

Sex (female) (n, \%)

Age (years) (mean $\pm S D)$

Duration of the inflammatory syndrome (months) (mean \pm SD)

Referring departments

Internal medicine $(\mathrm{n}, \%)$

Rheumatology (n, \%)

Infectious diseases ( $n, \%)$

Other (n, \%)

Past medical history

Tobacco consumption (n, \%)

Alcohol abuse (n, \%)

Obesity $\left(\mathrm{BMI}>30 \mathrm{~kg} / \mathrm{m}^{2}\right)(\mathrm{n}, \%)$

Non-infectious inflammatory diseases ( $n, \%)$

Malignancies (n, \%)

Baseline clinical symptoms

Joint symptoms (n, \%)

Weight loss ( $n, \%)$

Fever $>38.5^{\circ} \mathrm{C}(\mathrm{n}, \%)$

Patients with no clinical signs ( $n, \%)$

Baseline biological characteristics

CRP mean level $(\mathrm{mg} / \mathrm{L})($ mean $\pm \mathrm{SD})$

CRP minimum level $(\mathrm{mg} / \mathrm{l})($ mean $\pm \mathrm{SD})$

Mean duration of increased CRP (mg/l) (months \pm SD)

Patients under glucocorticoid treatment before PET/CT $(n, \%)$
Available

data

317

97 (30.6\%)

60 (18.9\%)

46 (14.5\%)

$114(36.0 \%)$

317

$91(28.7 \%)$

19 (6.0\%)

$39(12.3 \%)$

44 (13.9\%)

41 (12.9\%)

317

$150(47.3 \%)$

$90(28.4 \%)$

74 (23.3\%)

24 (7.6\%)

317

$91( \pm 59)$

$46( \pm 46)$

$5.2( \pm 12.7)$

317

$57(18.0 \%)$ 
Diagnosis strategy details

Positive antinuclear antibodies ( $n, \%$ of all patients)

$61(19.2 \%)$

Number of investigations before ${ }^{18}$ F-FDG-PET/CT (median, [IQR])

317

$4[2-6]$

Number of investigations after ${ }^{18}$ F-FDG-PET/CT (median [IQR])

317

$1[0-2]$

No investigation after ${ }^{18}$ F-FDG-PET/CT ( $\left.n, \%\right)$

Deaths

$S D$, Standard deviation; IQR, Interquartile range [25-75]; BMI, Bone Mass index. Death was collected after a prolonged follow-up, when available. 